(62,2\%); Chấn thương các loại (20,02\%); Sốt virus $(11,75 \%)$ và bệnh lý hô hấp $(8,34 \%)$. Số BN nặng cân HSCC chiếm...\%.

- Một số yếu tố ảnh hưởng đến mô hình bệnh tật BN vào cấp cứu tại BVĐK QT VMPQ: (i). Khách du lịch trong và ngoài nước; (ii). Thói quen, tập quán sinh hoạt đi lại của dân địa phương và của khách du lịch; (iii). Môi trường tại $P Q$ với đặc thù là khí hậu biển, chia hai mùa mưa và mùa khô rõ rệt.

\section{KHUYẾN NGHI}

- Hệ thống y tế trên Đảo cân chuẩn bị đây đủ các phương tiện cấp cứu, thuốc men phù hợp với mô hình bệnh tật tại địa phương.

- Xây dựng mô hình hệ thống cấp cứu tiên viện - HSTC tại chỗ - Vận chuyển BN về đất liền an toàn.

\section{TÀI LIẸU THAM KHẢO}

1. Cục quản lý khám chữa bệnh BYT (2017), Hướng dẫn mã hóa bệnh tật, tử vong theo ICD 10.
2. Lưu Phương Dung, Lê Thị Phương Mai (2017) "Mô hình bệnh tât của của người dân đến khám tại Bênh viên huyền Kỳ Anh (Hà Tĩnh), Tam Kỳ̀ (Quảng Nam) và Năm Căn (Cà Mau), giai đoạn 2014-2015", Tap chí Y hoc dư phòng, 6(27), Tr. 35 - 39.

3. Phan Minh Phú, Bùi Mạnh Côn, Hông Tuấn An, Đoàn Vương Kiệt (2016), "Khảo sát mô hình bệnh tật và tử vong tại bệnh viện An Bình năm 2014", Tap chí Y hoc TP HCM, 5 (20), Tr. 149.

4. Đố Than̉h Thúy (2018), "Khảo sát mô hình bênh tật tại khoa HSTC-CĐ tại BVĐK trung tâm Tiên Giang" "Tap chí y học thực hành, 15(74), tr.20 - 26.

5. Nguyển Trân Hữu Tuấn, Mai Hồ Duy và CS (2016), "Khảo sát mô hình bệnh tật tại Khoa cấp cứu tông hợp, BVĐK khu vực Hóc Môn năm 2015", Tạp chí y học thực hành, 12(745), tr.22 - 23.

6. Huỳnh Ngọc Thành (2017), Mố hình bệnh tật tại Bêenh viện II Lâm Đồng giai đoạn 2013 - 2017 và một số yếu tố liên quan, Luận văn Thạc sĩ Y học, trường Đai hoc $Y$ dược Huế

7. Amber Mehmood et al (2018), "Assessment of pre-hospital emergency medical services in lowincome settings using a health systems approach", International Journal of Emergency Medicine, 6(207), pp. 2-10.

\title{
MộT Số ĐĂC ĐIỂM CẤU TRÚC SỌ MẠT Ở NGƯỜI KINH TRƯỞNG THÀNH 18-25 TUỔI HẠNG III XƯƠ'NG HÀM TRÊN KÉM PHÁT TRIỂN
}

\section{TÓM TẮT}

Mục tiêu: Nghiên cứu mô tả cắt ngang được thực hiện nhằm xác định một số đăc điểm cấu trúc so mặt người Kinh trưởing thành từ 18-25 tuổi trên phim sọ nghiêng hạng III xương kém phát triển xương hàm trên. Đối tượng và phương pháp nghiên cứu: Nghiên cứu mồ tả cắt ngang trên 58 đối tượng nghiên cứu bao gồm 28 nam và 30 nữ trên phim so măt nghiêng. Kết quả nghiên cứu: Góc SNA ở nam là $77,52 \pm 1,60^{\circ}$, ở nữ là $77,74 \pm 1,58^{\circ}$; Góc SNB ở nam là $81,18 \pm 2,34^{\circ}$, ở nữ là $80,94 \pm 2,30^{\circ}$; Góc ANB ở nam là

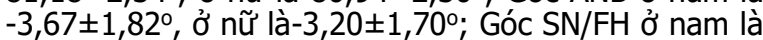
$10,29 \pm 2,67^{\circ}$, ở nữ là $10,18 \pm 2,77^{\circ} ;$ Góc S-Gn/FH ở nam là $57,89 \pm 3,81^{\circ}$, ở nữ là $57,37 \pm 2,58^{\circ} ;$ Góc U1/FH ở nam là $-118,44 \pm 11,59^{\circ}$, ở nữ là $118,00 \pm 6,78^{\circ}$; Góc U1/PP ở nam là $117,96 \pm 7,85^{\circ}$, ở nữ là $118,81 \pm 7,61^{\circ}$; Góc U1/OP ở nam là $135,17 \pm 13,22^{\circ}$, ở nữ là $133,89 \pm 11,09^{\circ}$. Kết luận: Góc SNA $<80^{\circ}$ (kém phát triển xương hàm trên), không có sự khác biệt giữa nam và nữ của các góc SNA, SNB, $A N B, S N / F H, S-$ $\mathrm{Gn} / \mathrm{FH}, \mathrm{U1} / \mathrm{FH}, \mathrm{U} 1 / \mathrm{PP}$ và U1/OP. Góc lệch nền sọ và góc trục mặt lớn hơn người Nepal nhưng nhỏ hơn

${ }^{1}$ Trường Đại học Y Hà Nội

${ }^{2}$ Bệnh viện 198, Bộ Công An

Chịu trách nhiệm chính: Hà Hải Anh

Email: dr.haianh8383@gmail.com

Ngày nhân bài: 5/9/2021

Ngày phản biên khoa hoc: 29/9/2021

Ngày duyệt bài: 9/10/2021 người Caucasian, Bắc Mỹ. Góc trục răng cửa hàm trên có xu hướng song song với trục mặt.

Tư khóa: Góc sọ mặt, phân tích phim sọ mặt nghiêng.

\section{SUMMARY \\ CHARACTERISTICS OF CRANIOFACIAL INDEXES OF KINH ETHNIC ALDUTS FROM 18 TO 25 YEARS WITH SKELETAL III CLASS AND UNDERDEVELOPED MAXILLA}

Purpose:A cross-sectional was conducted to determine some craniofacial indexes of Kinh ethnic adults from 18 to 25 years old with skeletal III class and underdeveloped maxilla. Materials and methods:A cross-sectional of 58 subjects (28 males and 30 females) ethnic alduts aged $18-25$ years on lateral cephalometric film. Results: SNA angle in male was $77,52 \pm 1,60^{\circ}$, in female was $77,74 \pm 1,58^{\circ}$; SNB angle in male was $81,18 \pm 2,34^{\circ}$, in female was $80,94 \pm 2,30^{\circ}$; ANB angle in male was $-3,67 \pm 1,82^{\circ}$, in female was $-3,20 \pm 1,70^{\circ} ; \mathrm{SN} / \mathrm{FH}$ angle in male was $10,29 \pm 2,67^{\circ}$, in female was $10,18 \pm 2,77^{\circ} ; \mathrm{S}-\mathrm{Gn} / \mathrm{FH}$ angle in male was $57,89 \pm 3,81^{\circ}$, in female was $57,37 \pm 2,58^{\circ} ; \mathrm{U} 1 / \mathrm{FH}$ anlge in male was $118,44 \pm 11,59^{\circ}$, in female was $118,00 \pm 6,78^{\circ}$; U1/PP angle in male was $117,96 \pm 7,85^{\circ}$, in female was $118,81 \pm 7,61^{\circ} ; \quad U 1 / O P$ anlge in male was $135,17 \pm 13,22^{\circ}$, in female was $133,89 \pm 11,09^{\circ}$. Conclusions: The results showed that SNA angle $<80^{\circ}$ (underdeveloped maxilla), was not different 
between male and female in angles SNA, SNB, ANB, $\mathrm{SN} / \mathrm{FH}, \mathrm{S}-\mathrm{Gn} / \mathrm{FH}, \mathrm{U} 1 / \mathrm{FH}$, U1/PP and U1/OP. SN/FH and $\mathrm{S}-\mathrm{Gn} / \mathrm{FH}$ angles in Kinh ethnic people of Vietnam were larger than Nepalese but lower than Caucasian, Noth America.

Keywords: Craniofacial, lateral cephalometric analysis.

\section{I. ĐặT VẤN ĐỀ}

Sai khớp cắn loại III là một loại sai khớp cắn thường gặp trong lâm sàng nắn chỉnh răng. Tại Việt Nam, theo nghiên cứu của Cao Thị Hoàng Yển (2007) [1] trên đối tượng sinh viên Đại học Y Hà Nội lứa tuổi 18 - 20 cho thấy: Phân bố về phân loại khớp cắn theo Angle có kết quả: $\mathrm{CL}_{\mathrm{I}}$ : 58,33\%; CLII: 23,33\%; CLIII: 18,34\%.

Phương pháp điêuu trị hạng III xương ở bệnh nhân trưởng thành bao gồm chỉnh nha ngựy trang đơn thuần hoặc chỉnh nha kết hợp phẩu thuật. Kết quả cuối cùng hướng tới cần đảm bảo cả về yếu tố chức năng và yếu tố thẩm mỹ. Vị trí của răng cửa trên ảnh hưởng trực tiếp đến vị trí môi, đóng vai trò xác định cung cười [3]. Trong quá trình điều trị hạng III, đặc biệt là hạng III xương bằng phương pháp chỉnh nha ngụy trang, việc kiểm soát trục thân răng cửa hàm trên đạt được kết quả tối ưu về mặt thẩm mỹ mà vấn đảm bảo sức khoẻ răng miệng là một trong những yếu tố quan trọng. Để xác định được cơ học vàvị trí răng cửa trên, các nhà chỉnh nha cần phải hiểu và xác định rõ tình trạng ban đầu của bênh nhân. Với những lý do trên, chúng tôi tiến hành nghiên cứu đề tài: "Một số đặc điểm cấu trúc sọ mặt ở người Kinh trưởng thành 18-25 tuổi hạng III xương hàm trên kém phát triển", với mục tiêu: Mô tả một số chỉ số sọ mặt trên phim sọ nghiêng ở người Kinh trưởng thành tù 18-25 tuổi có tương quan xương loại III do kém phát triển xương hàm trên.

\section{II. ĐỐI TƯợNG VÀ PHƯƠNG PHÁP NGHIÊN CỨU \\ 2.1. Đối tượng nghiên cứu}

- Tiêu chuẩn lựa chọn: Đối tượng có tuổi từ 18-25, có tương quan xương hang III do kém phát triển xương hàm trên với góc $A N B<0$, góc $\mathrm{SNA}<80$; không bị dị tật bẩm sinh vùng hàm mặt; chưa từng điều trị chỉnh nha; chưa từng điểu trị chỉnh hình xương vùng hàm mặt; không bị chấn thương vùng hàm mặt; có đầy đủ các răng vĩnh viễn (không tính răng hàm lớn thứ 3 ); phim có độ sáng tối và độ tương phản tốt; tư thế chụp đúng: đầu tư thế tự nhiên. khớp cắn ở tư thể lồng múi tối đa, môi tư thế nghỉ; thấy rõ được cấu trúc mô xương và mô mềm; nhìn rõ được các mốc giải phẫu nghiên cứu.

- Tiêu chuẩn loại trừ: Không thoả mãn tất cả các tiêu chuẩn lựa chọn.

\subsection{Phương pháp nghiên cứu}

- Nghiên cứu được thiết kế theo phương pháp mô tả cắt ngang.

- Thời gian nghiên cứu: từ 07/2020 đến 10/2021

- Địa điểm nghiên cứu: Trung tâm kĩ thuật cao khám chữa bệnh Răng Hàm Mặt, nhà $A 7$ Viện Đào tạo Răng Hàm Mặt, Trường Đại học Y Hà Nội.

Chọn trong hồ sơ bệnh án bênh nhân được thăm khám tại Trung tâm kỹ thuật cao A7, Viện Đào tạo Răng Hàm Mặt có chụp phim sọ nghiêng từ $01 / 01 / 2018$ đến ngày $31 / 5 / 2021$, chúng tôi chọn mẫu có chủ đích của 58 đối tượng đủ tiêu chuẩn lựa chọn bao gồm 28 nam và 30 nữ.

- Các điểm mốc giải phẫu: Điểm giữa hố yên (Sella $-\mathrm{S}$ ), điểm khớp trán mũi (Nasion-N), điểm lỗ ống tai ngoài (Porion-Po), điểm dưới ổ mắt (Or), điểm gai mũi trước (Anterior nasal spineANS), điểm gai mũi sau (Posterior nasal spinePNS), Điểm A (Subspinale), Điểm B (Submental), điểm dưới cằm (Gnathion $-G n$ ), mặt phẳng Frankfort, mặt phẳng xương hàm trên (PP), mặt phẳng cắn $(\mathrm{OP})$ và trục răng cửa hàm trên $\mathrm{U} 1$.

- Các góc cấu trúc sọ mặt: Góc SNA, SNB, ANB, $\mathrm{SN} / \mathrm{FH}, \mathrm{S}-\mathrm{Gn} / \mathrm{FH}, \mathrm{U1} / \mathrm{FH}$, U1/PP và góc U1/OP.

- Các góc được đo bằng phần mềm chuyên dụng Auto Cad 2015 và xử lý thống kê bằng spss 20.0.

2.3. Đạo đức nghiên cứu. Tuân thủ đầy đù các nguyên tắc đạo đức của nghiên cứu y học. Đối tượng nghiên cứu tự nguyện, không bị ép buộc. Mọi thông tin của đối tượng nghiên cứu được giữ bí mật, không tiết lộ khi không có sự đồng ý của đối tượng, không sử dụng vào mục đích khác.

\section{KẾT QUẢ NGHIÊN CứU}

Nghiên cứu được thực hiện trên58 đối tượng tham gia nghiên cứu bao gồm 28 nam và 30 nữ người Kinh từ 18-25 tuổi hạng III xương hàm trên kém phát triển.

Bảng 3.1. Giá trị trung bình góc xương hàm trên, góc xương hàm dưới, góc liên xương giữa hàm trên và hàm dưới

\begin{tabular}{|c|c|c|c|c|c|c|c|}
\hline \multirow{2}{*}{ Chỉ số $\left({ }^{\circ}\right)$} & \multicolumn{2}{|c|}{ Nam } & \multicolumn{2}{|c|}{ Nữ } & \multicolumn{2}{|c|}{ Chung } & \multirow{2}{*}{$\mathbf{p}$} \\
\hline & $\overline{\mathrm{X}}$ & SD & $\bar{x}$ & SD & $\bar{x}$ & SD & \\
\hline SNA & 77,52 & 1,60 & 77,74 & 1,58 & 77,63 & 1,58 & 0,5909 \\
\hline
\end{tabular}




\begin{tabular}{l|l|l|l|l|l|l|l} 
SNB & 81,18 & 2,34 & 80,94 & 2,30 & 81,06 & 2,29 & 0,6811 \\
ANB & $-3,67$ & 1,82 & $-3,20$ & 1,70 & $-3,44$ & 1,76 & 0,1721
\end{tabular}

Nhânn xét: Giá trị trung bình chỉ số góc xương hàm trên (SNA), góc xương hàm dưới (SNB), góc liên xương giữa hàm trên và hàm dưới (ANB) của nam giới nhỏ hơn nữ giới. Sự khác biệt về các chỉ số góc trên không có ý nghĩa thống kê giữa nam giới và nữ giới $(p>0,05)$.

Bảng 3.2. Giá trị trung bình góc lệch nền sọ, góc giữa trục mặt và mặt phẳng FH

\begin{tabular}{|c|c|c|c|c|c|c|c|}
\hline \multirow{2}{*}{ Chỉ số ( $\left.{ }^{\circ}\right)$} & \multicolumn{2}{|c|}{ Nam } & \multicolumn{2}{|c|}{ Nũ̃ } & \multicolumn{2}{|c|}{ Chung } & \multirow[b]{2}{*}{$\mathbf{p}$} \\
\hline & $\overline{\mathrm{x}}$ & SD & $\bar{x}$ & SD & $\bar{x}$ & SD & \\
\hline SN/FH & 10,29 & 2,67 & 10,18 & 2,77 & 10,24 & 2,69 & 0,4412 \\
\hline S-Gn/FH & 57,89 & 3,81 & 57,37 & 2,58 & 57,63 & 3,22 & 0,9934 \\
\hline
\end{tabular}

Nhận xét: Bảng 3.2 giá trị trung bình của góc lệch nền so (SN/FH), góc giữa trục mặt và mặt phẳng $\mathrm{FH}(\mathrm{S}-\mathrm{Gn} / \mathrm{FH})$ của nam giới cao hơn nữ giới. Sự khác biệt về các chỉ số góc trên không có ý nghĩa thống kê giữa nam giới và nữ giới $(p>0,05)$.

Bảng 3.3. Giá trị trung bình góc trục răng cửa hàm trên và mặt phẳng $F H$, góc trục răng cửa hàm trên và mặt phẳng hàm trên, góc trục răng cửa hàm trên và mặt phẳng nhai

\begin{tabular}{|c|c|c|c|c|c|c|c|}
\hline \multirow{2}{*}{ Chỉ số $\left({ }^{\circ}\right)$} & \multicolumn{2}{|c|}{ Nam } & \multicolumn{2}{|c|}{ Nũ̃ } & \multicolumn{2}{|c|}{ Chung } & \multirow[b]{2}{*}{$\mathbf{p}$} \\
\hline & $\overline{\mathrm{X}}$ & SD & $\overline{\mathrm{X}}$ & SD & $\overline{\mathrm{X}}$ & SD & \\
\hline U1/FH & 118,44 & 11,59 & 118,00 & 6,78 & 118,22 & 9,41 & 0,6845 \\
\hline U1/PP & 117,96 & 7,85 & 118,81 & 7,61 & 118,39 & 7,67 & 0,4056 \\
\hline U1/OP & 135,17 & 13,22 & 133,89 & 11,09 & 134,51 & 12,16 & 0,2332 \\
\hline
\end{tabular}

Nhận xét: Bảng 3.3 cho thấy, giá trị trung bình chỉ số góc trục răng cửa hàm trên và mặt phẳng $\mathrm{FH}(\mathrm{U} 1 / \mathrm{FH})$, góc giữa trục răng cửa hàm trên và mặt phẳng nhai (U1/OP) của nam giới cao hơn nữ giới. Trong đó, giá trị trung bình góc trục răng cửa hàm trên và mặt phẳng hàm trên (U1/PP) của nữ giới cao hơn nam giới. Sự khác biệt về các chỉ số góc trên không có ý nghĩa thống kê giữa nam giới và nữ giới $(p>0,05)$.

\section{BÀN LUẬN}

4.1. Góc xương hàm trên, góc xương hàm dưới và góc liên xương hàm. Theo kết quả nghiên cứu thu được, góc xương hàm trên (SNA), góc xương hàm dưới (SNB) và góc liên xương hàm (ANB) ở cả hai giới lần lượt là $77,63 \pm 1,58^{\circ}, 81,06 \pm 2,29^{\circ}$ và $-3,44 \pm 1,76^{\circ}$. Khi so sánh với các chỉ số theo phân tích của Steiner, góc xương hàm trên (SNA) và góc liên xương hàm (ANB) ở người Caucasian lớn hơn người trưởng thành trong nghiên cứu này, tuy vậy góc xương hàm dưới (SNB) lớn hơn so với người Caucasian trong nghiên cứu của Steiner [4]. So sánh các góc tương quan xương với một số nghiên cứu trong nước cho thấy góc tương quan xương trong nghiên cứu của Nguyễn Phương Huyền (2017)[5] khác với kết quả của chúng tôi. Sự khác biệt là do cách chọn mẫu, đối tượng nghiên cứu của tác giả Nguyễn Phương Huyền chọn ngẫu nhiên, không phân loại theo tương quan xương, do vậy các chỉ số tương quan xương giống với giá trị trung bình của người trưởng thành. Kết quả nghiên cứu của chúng tôi tương đồng với nghiên cứu của Nguyễn Hồng

Thủy (2017)[6], khi thấy xương hàm dưới có xu hướng phát triển quá phát so với góc trung bình theo phân tích Steiner, tuy nhiên, trong nghiên cứu của chúng tôi góc xương hàm trên có xu hướng kém phát triển, nhưng trong nghiên cứu của Nguyễn Hồng Thủy thì góc xương hàm trên có giá trị giống với phân tích của Steiner trên người Caucasian. Góc SNA và SNB được dùng để đánh giá mối tương quan xương hai hàm, với nền sọ đặc trưng bởi đường $S N$ ít thay đổi khi trưởng thành, do vậy Steiner chọn những điểm của nền sọ trước như là đường tham chiếu cơ bản (điểm S-Sella và điểm $\mathrm{N}$ - Nasion).

Bảng 4.1. So sánh với một số tác giả trong nước

\begin{tabular}{|c|c|c|c|}
\hline Chỉ số & $\begin{array}{l}\text { Nguyễn } \\
\text { Phương } \\
\text { Huyên [5] }\end{array}$ & $\begin{array}{l}\text { Nguyễn } \\
\text { Hồng } \\
\text { Thủy[6] }\end{array}$ & $\begin{array}{l}\text { Hà Hải } \\
\text { Anh và } \\
\text { cộng sự }\end{array}$ \\
\hline SNA $\left({ }^{\circ}\right)$ & $82,52 \pm 3,36$ & $82,20 \pm 3,46$ & \multirow{2}{*}{$77,63 \pm 1,58$} \\
\hline $\mathrm{P}$ & $<0,001$ & $<0,001$ & \\
\hline SNB $\left({ }^{\circ}\right)$ & $79,16 \pm 3,58$ & $81,31 \pm 3,66$ & \multirow{2}{*}{$81,06 \pm 2,29$} \\
\hline $\mathrm{P}$ & $<0,05$ & $>0,05$ & \\
\hline ANB ( $\left.{ }^{\circ}\right)$ & $3,36 \pm 2,41$ & $0,90 \pm 2,75$ & \multirow{2}{*}{$-3,44 \pm 1,76$} \\
\hline$P$ & $<0,001$ & $<0,001$ & \\
\hline
\end{tabular}

Độ lệch nền sọ xác định góc giữa nền sọ trước Sella - Nasion và mặt phẳng Frankfort, trong nghiên cứu của chúng tôi, độ lệch nền sọ không có sự khác biệt giữa hai giới từ 18-25 tuổi. Khi so sánh với kết quả nghiên cứu của Jamal Giri [7] và Avinash Chaudhary [8] thực hiện trên người trưởng thành Nepal cho thây độ lệch nền sọ ở nữ lớn hơn nam có ý nghĩa thống kê. Chỉ số độ lệch nền sọ theo nghiên cứu của chúng tôi 
trên người Kinh trưởng thành lớn hơn so với người Nepal, sự khác biệt này có thể giải thích do khác biệt chủng tộc người trong mỗi nghiên cứu.

Bảng 4.2. So sánh góc lệch nền sọ với một số tác giả

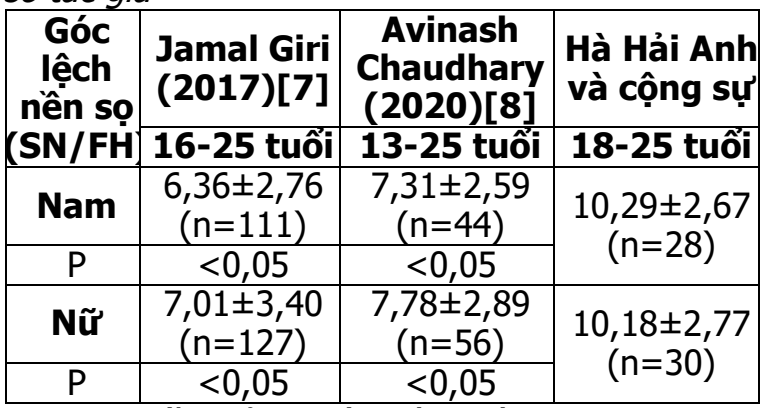

Theo kết quả nghiên cứu, góc trục mặt được xác định giữa đường nối Sella-Gnathion và mặt phẳng Frankfort, không có sự khác biệt góc trục mặt giữa nam và nữ ở người Kinh trưởng thành từ 18-25 tuổi. Nghiên cứu cho thấy không có sự khác biệt có ý nghĩa thống kê góc trục mặt ở người trưởng thành giữa nam và nữ. Tuy nghiên chỉ số góc trục mặt ở người Kinh trưởng thành nhỏ hơn so với người Caucasian, Bắc Mỹ trong phân tích của Down (2006) [4] và trẻ 12 tuổi người dân tộc Kinh trong nghiên cứu của Vũ Thị Xuân (2017). Kết quả này cho thãy trục mặt ở người Kinh có xu hương xoay ra sau nhiều hơn chủng tộc khác, nhưng xu hướng tăng trưởng nhìn chung của xương hàm dưới ra trước và xuống dưới.

4.2. Góc trục răng cửa hàm trên với mặt phẳng Frankfort, mặt phẳng hàm trên và mặt phẳng nhai. Theo kết quả nghiên cứu, sự khác biệt góc răng cửa hàm trên với mặt phẳng Frankfort (U1/FH), với mặt phẳng hàm trên (U1/PP), với mặt phẳng nhai (U1/OP) giữa nam và nữ không có sự khác biệt có ý nghĩa thống kê. Góc trục răng cửa hàm trên với các trục tham chiếu cho thấy mức độ nghiêng theo hướng trước - sau của răng, trục răng cửa hàm trên có góc so với mặt phẳng Frankfort $(\mathrm{FH})$ có $\mathrm{xu}$ hướng song song với trục mặt theo phân tích Down, trong nghiên cứu này, chúng tôi nhận thấy góc trục răng cửa hàm trên và mặt phẳng Frankfort gần như song song với trục mặt, do vậy có sự phù hợp giữa trục răng cửa hàm trên ở người Kinh trưởng thành từ 18-25 tuổi và người Caucasian, Bắc Mỹ từ 12-17 tuổi [4]. Theo nghiên cứu của Ricketts [4], góc truc răng cửa hàm trên không thay đổi theo tuổi, điều này cũng cho thấy có sự tương đồng trong xu hướng tăng trưởng mặc dù khác chủng tộc, tuy nhiên mức độ gia tăng và tỷ lệ tăng trưởng thì có sự khác nhau giữa các chủng tộc người.

\section{KẾT LUÂN}

Nghiên cứu trên 58 đối tượng người Kinh trưởng thành từ 18-25 tuổi trên phim sọ nghiêng, chúng tôi có một số kết luận sau: Góc SNA $<80^{\circ}$ (kém phát triển xương hàm trên), không có sư khác biệt giữa nam và nữ của các góc SNA, SNB, ANB, SN/FH, S-Gn/FH, U1/FH, U1/PP và U1/OP. Góc lệch nền sọ và góc trục mặt lớn hơn người Nepal nhưng nhỏ hơn người Caucasian, Bắc Mỹ. Góc trục răng cửa hàm trên có xu hướng song song với trục mặt và tương đồng với với chủng người Caucasian.

LờI CẢM ƠN. Xin bày tỏ lòng biết ơn sâu sắc đến các đối tượng đồng ý tham gia nghiên cứu và Trung tâm Kỹ thuâat cao $A 7$, Viện Đào tạo Răng Hàm Mặt, Trường Đại học Y Hà Nội, nhóm xử lý số liệu, các cơ quan cùng các thầy cô bạn bè đã giúp đõ tận tình, tạo điều kiên thuận lợi cho tôi thực hiện và hoàn thành nghiên cứu.

\section{TÀI LIỆ THAM KHẢO}

1. Cao Thị Hoàng Yến (2007). Nhân xét tình trạng khớp cắn của sinh viên đai học Y Hà Nội lứa tuối 18 - 20, Luân văn tốt nghiệp bác sĩ Răng Hàm Mặt, Đai hoc Y Hà Nội.

2. W. J. S. Kerr and J. M. O'Donnell. Panel Perception of Facial Attractiveness, British Journal of Orthodontics, 1990;17(4).

3. Ronald E. Goldstein and Stephen J. Chu (2018). Ronald E. Goldstein's Esthetics in Dentistry, Third Edition.

4. Jacobson A and Jacobson R. L (2006) Radiographic cephalometry from basics to 3-D imaging, second edition, Quintessence Publishing Co Inc, Ilinois.

5. Nguyển Phương Huyên, Nguyễn Thị Thu Phương, Hoàng Tuấn Linh (2017). Một số chì số so-mặt trên phim sọ nghiêng từ xa theo phân tích Steiner ở nhóm người Việt tuổi 18-25, Tap chí Y dược học quân sự số chuyên đề hình thái học, $42,489-494$.

6. Nguyễn Hồng Thủy, Trân Thị Mỹ Hạnh và Tống Minh Sơn (2018). Một số chỉ số so - măt trên phim so nghiêng từ xa kỹ thuâtt số ở người Việt độ tuổi 18 - 25 sai khớp cắn loại III theo angle, Tap chí $Y$ dược học quân sự số chuyên đề hình thái học, 42, 156-159.

7. Jamal Giri et al (2017). Angular relationship between Frankfort Horizontal Plane and sellaNasion Pane in Nepalese orthodontic patients: A cephalometric study, Orthodontic Journal of Nepal, $7(1), 13-17$.

8. Avinash Chaudhary et al (2020). A cephalometric study of $\mathrm{FH}-\mathrm{SN}$ angle in different sagittal skeletal patterns among patients seeking orthodontic treatment, Acta Scientific Dental Sciences, 4(11), 115-119. 